\title{
AS RELAÇÕES INTERPESSOAIS DO ORIENTADOR DE MESTRADO: UMA ANÁLISE DISCURSIVA ATRAVÉS DO SISTEMA DE TRANSITIVIDADE
}

Silvia Adélia Henrique Guimarães é professora no Município do Rio de Janeiro e doutoranda em Letras na UERJ.

E-mail: sguimaraes05@hotmail.com

\section{Resumo}

Este artigo apresenta uma pesquisa sobre o discurso de orientadores de mestrado em Linguística sobre sua prática. A análise linguística, pautada no Sistema de Transitividade da LSF, sugere que esses profissionais atuam na idiossincrasia. Além disso, possibilita: a) a reflexão dos sujeitos sobre seus papéis e atribuições; e b) a atualização do aporte teórico, aplicado a um tema ainda pouco explorado.

\begin{abstract}
This paper presents research on the discourse of guiding Masters in Linguistics on their practice. Linguistic analysis, based on the Transitivity System of LSF, suggests that these professionals work in idiosyncrasy. Also, allows: a) the reflection of the subjects about their roles and responsibilities; b) update the theoretical framework applied to a still relatively unexplored subject.
\end{abstract}

\section{1) Introdução}

Este trabalho apresenta um recorte da minha dissertação de mestrado, que objetivou analisar o discurso de seis professores-orientadores de mestrado, no Rio de Janeiro. A pesquisa parte do seguinte nicho: não haver espaços abrangentes para a voz do orientador sobre o seu fazer, apesar de sua importância social.

Os poucos trabalhos que contêm a voz do orientador aparecem ainda em forma de relatos de experiências pessoais, ou promovendo denúncias contra as mudanças político-educacionais na pós-graduação, as quais não consideram suas experiências sobre o assunto (FLECHA, 2003; BIANCHETTI E MACHADO, 2006). Vozes essas que surgem, portanto, ainda sem a força de representação de uma categoria.

Tais relatos sugerem que estudos sobre o tema precisam ser divulgados (SAVIANI, 2006), o que aponta que muitos debates sobre o papel social desse profissional devem ser promovidos, para que os trabalhos deixem de ser isolados, a fim de, inclusive, sistematizar os problemas recorrentes e lutar por soluções práticas. Portanto, o objetivo primeiro desta pesquisa foi "tocar no assunto".

O segundo objetivo da pesquisa foi procurar os discursos que se repetiriam na fala desses orientadores, o qual foi desmembrado em duas perguntas centrais: apesar de não haver um protocolo específico a que devam seguir, haveria formas e procedimentos que se repetiriam na fala desses orientadores? Em que aspectos os discursos se destoariam?

Considero, portanto, que as temáticas várias que emergiram no corpus partiram de alguma necessidade que os orientadores pudessem ter de se posicionarem, de revelarem discursivamente algo do seu papel social. Oportunidade para usarem sua voz. E aqui, divulgamos uma delas: as relações interpessoais dos orientadores.

Considerei que o campo semântico relações interpessoais não tenha sido um tema diretamente evocado pelas três perguntas feitas aos participantes, quais sejam: 
"Por que orienta?", "Como definiria a função do orientador?" e "Como se sente em relação a isso?".

Assim sendo, os dados, organizados no campo semântico relações interpessoais, foram tratados linguisticamente pelo Sistema de Transitividade da Linguística Sistêmico Funcional (HALLIDAY, 1994) e discutidos à luz da Análise Crítica do Discurso (FAIRCLOUGH, 1999).

Objetivando organizar os resultados, este trabalho está dividido em seções. Em primeiro momento, trouxe um embasamento teórico para os principais achados emergidos dos dados; em segundo momento, contextualizei o trabalho metodologicamente para, em seguida, apresentar e discutir os dados. Ao final, trouxe algumas considerações, optando por não denominá-las "conclusão", principalmente pelo caráter seminal da pesquisa, esperando, portanto, estar contribuindo de maneira relevante às pesquisas em Linguagem.

\section{2) Pressupostos teóricos}

Halliday, precursor da Linguística Sistêmico-Funcional (doravante LSF), defende que a língua se organiza em torno de redes de opções relativamente independentes, cujas funções constituem e também são constituídas pelas operações de escolhas no nível da léxico-gramática. Para o teórico, essas escolhas: a) são feitas a partir de uma rede de paradigmas disponíveis; b) ocorrem tanto em níveis conscientes quanto subconscientes em graus variados; c) realizam o potencial semântico do sistema; d) produzem um determinado significado (HALLIDAY, 1994; NEVES, 1997; GOUVEIA, 2009).

A LSF concebe a linguagem como semiótica social: entende-a como um recurso de construção e interpretação de significados em contextos sociais. Nesse prisma, a construção de significados é motivada social e culturalmente e, para isso, apresenta-se como ferramenta para o estudo da linguagem a partir de uma perspectiva sóciosemiótica. ${ }^{1}$

Segundo Halliday, a língua se organiza em torno de duas formas principais de construção de sentido: a ideacional (ou reflexiva) e a interpessoal (ou ativa), chamadas de metafunções. As metafunções cumprem dois propósitos: entender a representação do mundo externo ou interno do falante (metafunção ideacional) e entender as relações do falante (metafunção interpessoal). A essas duas metafunções é agregada uma terceira, a textual, cujo objetivo é analisar a materialidade dos textos - falados ou escritos.

As metafunções realizam(-se)(n)um contexto de situação através do registro, tendo em vista as variáveis contextuais campo, relações e modo. Em suma, (a) $\mathrm{O}$ Campo do discurso refere-se à natureza da atividade social; aqui, inclui-se o tema e a atividade do agente discursivo; ${ }^{2}$ (b) as Relações identificam quem participa de determinado evento discursivo, o status e o papel dos participantes - direciona a análise

\footnotetext{
${ }^{1}$ Há que se destacar que a semiótica, definida como estudo geral dos sistemas de signos, possibilita que a língua, na LSF, seja um dos vários sistemas de produção de significado possíveis.

${ }^{2}$ Para ilustrar esse conceito, Ghio e Fernandez citam que a ação verbal durante o jogo de futebol é distinta da discussão sobre futebol no bar (2005, p.37).
} 
aos papéis desempenhados por esses participantes; e (c) o Modo define o papel e a natureza da linguagem na interação, concentrando-se na função e no canal do texto em determinado contexto - refere-se às construções simbólicas dos interactantes, ao uso da língua propriamente dita (GHIO E FERNANDEZ, 2005).

Além desses conceitos, na LSF é imprescindível definir o conceito de texto. Este se refere a "qualquer instância de linguagem viva que tenha um papel dentro de um contexto de situação, podendo ser falada ou escrita e expressada por qualquer meio de expressão que se possa imaginar" (HALLIDAY \& HASAN, 1989, p 10). Esse texto terá, portanto, uma relação dialética com o contexto, mas também terá sua realização através de fraseados (wordings). Esses fraseados são definidos em Halliday como sequências gramaticais, ou sintagmas que contêm itens lexicais e gramaticais, os quais realizam os significados nas frases (HALLIDAY, 1994; HALLIDAY \& MATHIESSEN, 2004).

Halliday sugere, portanto, uma gramática que proponha categorias de base semântica. Por isso, a LSF utiliza a oração como base de análise, entendendo-a como unidade principal da léxico-gramática e polo motivador das realizações de constituição do sistema (GOUVEIA, 2009, p. 8). Nessa perspectiva, a oração é materializada pelo sistema de transitividade.

O sistema de transitividade constrói o mundo da experiência através de um conjunto gerenciável de tipos de processos. Cada tipo de processo representa seu próprio modelo ou esquema para construir um domínio de experiência particular (HALLIDAY, 1994, p. 106). Esse sistema é realizado através dos processos material, mental e relacional, os principais; comportamental, verbal e existencial, os intermediários. Cada um desses processos apresenta três elementos: o processo, os participantes e a circunstância. Esses processos serão explicados pelo modelo teórico de Halliday (1994) e pela revisão/ampliação de sua proposta (HALLIDAY E MATHIESSEN, 2004), mas exemplificados através de orações extraídas do corpus desta pesquisa, objetivando familiarizar o leitor com o contexto das construções discursivas encontradas nesta pesquisa.

O processo material é o processo de fazer. Nele pode haver um ator, uma meta, uma extensão e um beneficiário: "em geral (circunstância) eles (ator) fazem (processo material) [o trabalho] (meta)". O mental é o processo do sentir, que pode apresentar um experienciador e um fenômeno para o processo: " $\mathrm{eu}$ (experienciador) acho (processo mental de percepção) [que ele entra com déficit maior] (fenômeno)". Este processo pode ser de cognição (decisão e compreensão), percepção (observação de fenômenos) e afeição (sentimentos); O processo comportamental é o processo de agir; tem um comportante e uma extensão/fenômeno: "pelas conversas que eu (comportante) tenho (processo comportamental) com meus colegas (extensão)". O verbal é o processo do dizer; tem um dizente e um alvo; sendo verbiagem a mensagem propriamente dita: " $e u$ (dizente) diria (processo verbal) que setenta por cento são boas são boas pesquisas (verbiagem)". O processo existencial é o processo de existir. Nele, há um participante/existente: "e aí tem (processo existencial) o sistema CAPES (existente)". Todos os processos podem ser determinados por uma circunstância (Halliday, 1994). 
Os processos materiais, mentais e relacionais são, na Teoria de Halliday, os três processos principais que representam as ações humanas. $\mathrm{Na}$ fronteira entre esses processos surgem outros: os comportamentais, os verbais e os existenciais.

A Análise Crítica do Discurso (ACD) tem em comum com a LSF a linguagem em uso. Para a Análise Crítica do Discurso, a relação entre linguagem e sociedade é interna e dialética, ou seja, as estruturas sociais tanto informam como também são informadas pelos textos, possibilitando que o discurso influencie na transformação ou reprodução de tais estruturas. Neste prisma, a linguagem não é apenas uma forma de representar o mundo, mas também forma de ação sobre o mundo, o que leva a ACD a concentrar-se no estudo das dimensões discursivas da mudança social (FAIRCLOUGH, 2001).

Partindo dessa premissa, a ACD trabalha situações discursivas cuja prática social seja de relevância prática para a sociedade, tais como o discurso do educador, do profissional da saúde, dos políticos, das minorias..., relacionando as micro às macrointerações. Isso porque o discurso realiza um trabalho ideológico, ou seja: toda fala está carregada de representações ideológicas, revelando uma ideologia histórica e contextualmente localizada ${ }^{3}$. Sendo assim, a análise do discurso é interpretativa e explanatória, depreendendo questões a partir desses contextos, não podendo, portanto, afirmar uma verdade absoluta e inexorável, mas com possibilidades interpretativas e também de transformações (Fairclough \& Wodak, p. 271-280, apud DIJK, 2010, p. $115)$.

\section{3) Pressupostos metodológicos}

Este trabalho insere-se no paradigma qualitativo. É de natureza crítica, já que entende que "nenhum processo social pode ser compreendido de forma isolada, como uma instância neutra acima dos conflitos ideológicos da sociedade" (ALVEZMAZZOTTI 1999, 139). Apesar de não generalizar as interpretações, é capaz de sugerir como os dados, de nível micro (nível discursivo), podem estar relacionados ao macro (nível social) (FAIRCLOUGH, 2001). Contudo, para chegar a essas relações, o trabalho conta com informações quantitativas, sendo denominado quali-quantitativo.

Por não ter objetivado avaliar a prática do orientador, mas o discurso dele sobre o seu papel, possibilitando espaço de reflexão sobre o seu próprio fazer, a geração dos dados foi promovida a partir da voz de seis orientadores: dois de uma universidade federal (Cláudia e Fátima), dois de uma universidade estadual (Paulo e Raquel) e dois de uma universidade privada (Rafaela e Consuelo), os quais receberam nomes fictícios para terem suas identidades preservadas. Todos atuam no Rio de Janeiro, por ser onde resido, facilitando a pesquisa.

\footnotetext{
${ }^{3} \mathrm{O}$ termo ideologia não é conceituado na ACD de forma definitiva. As situações e contextos podem revelar ideologias, já que são também representações dos aspectos desse mundo. Nesse sentido, as ideologias contribuem para o estabelecimento e a manutenção das relações de poder, dominação e exploração (FAIRCLOUGH, 2001, 2003). À ideologia cabe o papel de sustentar as relações assimétricas de poder, reproduzindo a ordem social dos grupos dominantes e os indivíduos que a eles pertencem. Esse poder é estabelecido e/ou reproduzido, não pelo uso da força, mas pelo consenso, mediante "concessões ou meios ideológicos para ganhar seu consentimento" (Idem, 2001, p. 122).
} 
Os dados que guiaram a análise surgiram das perguntas "Por que orienta?", "Como você definiria a função do orientador nessa perspectiva?" e "Como se sente em relação a isso?". Em seguida, procedi à seleção de orações a partir da palavra-chave "orientar", bem como palavras derivadas (orientação, orientador...) e pronomes substantivos. A partir da seleção das orações, agrupei as mesmas por campos semânticos, organizando o corpus em categorias discursivas, o que possibilitaria estudar possíveis identidades de projeto ou idiossincrasias ${ }^{4}$ na prática social "orientar".

Apesar de terem surgido as categorias semânticas a) o fazer do orientador; b) suas relações interpessoais; c) suas motivações institucionais; d) o seu saber; e) sua relação com a pesquisa; e f) sua relação com modelos de orientação, neste artigo, abordo e discuto "Suas relações interpessoais" com total de 47 ocorrências compositoras do presente corpus, analisado pelo Sistema de Transitividade.

\section{4) Análise e discussão dos dados}

Ao situarem discursivamente o seu fazer interpessoal, os sujeitos desta pesquisa relacionaram seu papel basicamente ao Outro-aluno. Os dados sugerem que eles estabelecem esta relação orientador-aluno como uma relação sumária na função orientar.

Esta categoria, relação com o outro, foi a que mais agrupou processos nas questões não evocadas (assuntos que não apareceram nas perguntas formuladas para a pesquisa, mas que surgiram espontaneamente na fala dos participantes). Considerei essa espontaneidade importante para a análise dos dados, principalmente porque apenas dois dos seis sujeitos (Fátima e Raquel) não abordaram linguisticamente esse tema. Além disso, considero que o surgimento das ocorrências foi bastante significativo: 47 ocorrências, representando $29 \%$ do total do corpus.

Tendo em vista essas explicações iniciais, e lembrando que apenas os sujeitos Fátima e Raquel não aparecem no mapeamento deste tema, apresento a tabela 1, a seguir com a síntese dos dados para, em seguida, proceder às discussões.

\begin{tabular}{l|l|l|l|l|l|l|l|r} 
& Cognição & $\%$ & Afeição & $\%$ & Percepção & $\%$ & Total & $\%$ \\
\hline Consuelo & 3 & $16 \%$ & & & & & 3 & $16 \%$ \\
\hline Cláudia & 1 & $5 \%$ & 2 & $11 \%$ & 1 & $5 \%$ & 4 & $21 \%$ \\
\hline Paulo & 3 & $16 \%$ & 2 & $11 \%$ & 2 & $11 \%$ & 7 & $37 \%$ \\
\hline Rafaela & 4 & $21 \%$ & 1 & $5 \%$ & & & 5 & $26 \%$ \\
\hline Totais & 11 & $58 \%$ & 5 & $26 \%$ & 3 & $16 \%$ & 19 & $100 \%$
\end{tabular}

Tabela 1: Resumo das subcategorias dos processos mentais por sujeito

\footnotetext{
${ }^{4} \mathrm{O}$ dicionário Michaelis define assim: i.dios.sin.cra.si.a $s f$ ( $g r$ idiosygkrasía) 1 Med. Constituição individual, em virtude da qual cada indivíduo sofre diferentemente os efeitos da mesma causa. 2 Psicol. Qualquer detalhe de conduta peculiar a um indivíduo determinado e que não possa ser atribuído a processos psicológicos gerais, bem conhecidos. Var: idiocrasia. http://michaelis.uol.com.br/moderno/portugues/index.php?lingua=portuguesportugues\&palavra=idiossincrasia
} 


\section{1) O outro nos processos mentais}

Os processos mentais foram os mais recorrentes nas escolhas destes sujeitos, representando $40 \%$ dos processos utilizados. Neles os sujeitos "sabem" sobre o Outroaluno.

\subsection{1) Os mentais cognitivos}

Dos 19 processos mentais que se referiam às relações no fazer orientação, 11 foram de cognição (58\% das ocorrências). Apresento, a seguir, alguns exemplos para análise pontual, reiterando que os processos cognitivos "achar" ganham, em toda a análise, o valor de "pensar", "considerar":

\begin{tabular}{|c|c|}
\hline $\begin{array}{l}\text { (Rafaela:09) } \\
\text { (Rafaela:12) }\end{array}$ & $\begin{array}{l}\text { Então acho que na verdade o meu papel vai se desdobrando dependendo do } \\
\text { do do aluno } \\
\text { outros que precisam de um empurrão }\end{array}$ \\
\hline $\begin{array}{l}\text { (Paulo:17) } \\
\text { (Paulo:18) }\end{array}$ & $\begin{array}{l}\text { Ele quer queimar etapas. } \\
\text { Ele espera, espera que essa orientação seja TUdo pra ele. }\end{array}$ \\
\hline $\begin{array}{l}\text { (Consuelo:11) } \\
\text { (Consuelo:12) }\end{array}$ & $\begin{array}{l}\text { mas eu acho que é uma pessoa com quem você idealmente tem que se sentir } \\
\text { à vontade pra pra debater, pra comentar leituras, pra pedir ori- pedir ajuda } \\
\text { se precisar de ajuda, } \\
\text { Eu acho que (orientar) é muito afetivo também }{ }^{5} \\
\text { o interpessoal ali tem que funcio- você não pode NÃO gostar do seu } \\
\text { orientador acho que- ou de um orientando }\end{array}$ \\
\hline (Cláudia:19) & $\begin{array}{l}\text { eu vou ver ele crescendo com o que eu to ensinando, não no sentido de que } \\
\text { eu vá passar as coisas pra ele, mas no sentido de vê-lo descobrir coisas, } \\
\text { interagir com os pares, interagir comigo, }\end{array}$ \\
\hline
\end{tabular}

Nas orações principais, o experienciador foi o aluno (3x), das quais duas com fenômenos que atribuem sentidos de dependência ao aluno: (Rafaela:12) e (Paulo:18).

Em (Consuelo:12) há uma sugestão de afetividade em que o aluno é o experienciador (que se estende a uma relação de duas vias, em que o orientador também pode ser entendido como o experienciador). Os demais processos tiveram os fenômenos atribuídos às orações encaixadas.

Quatro das cinco ocorrências de orações encaixadas como extensão do sentido da principal revelam mais uma vez que o orientador "sabe" sobre seu papel, seja materializando, seja classificando, seja sentindo. Uma delas mostra mais uma vez, desde o experienciador da principal que o orientador "sabe" em nome do aluno (Paulo:18).

Nos 11 processos mentais cognitivos que se referem às relações no fazer orientação, encontra-se uma relação bipartida entre orientador/orientar e aluno; ou entre aluno e orientador/ações praticadas pelo orientador em sua atuação. Em alguns casos, um mesmo sujeito desenhou essa relação de acordo com os dois modelos, como "meu

\footnotetext{
${ }^{5}$ O Outro deste fragmento encontra-se em (Consuelo:12)
} 
papel vai se desdobrando" (Rafaela:09) e "outros que precisam de um empurrão" (Rafaela:12).

$\mathrm{O}$ aluno parece ser colocado em situação de dependência, mesmo quando o experienciador é o aluno, como em "ele crescendo com o que eu to ensinando" (Cláudia:19). ${ }^{6} \mathrm{O}$ aluno também é avaliado de forma negativa, mesmo quando cumpre um papel ativo, como em "(ele) quer queimar etapas" (Paulo:19); ou, ainda, em completa passividade em relação ao fazer do orientador: "Ele espera, espera que essa orientação seja TUdo pra ele" (Paulo:18).

Tais ocorrências parecem sugerir um orientador que, a partir de sua compreensão/cognição, representa o aluno de mestrado como alguém que a) depende do fazer do orientador (Rafaela, Paulo, Consuelo e Cláudia); b) quando atua, o faz de forma equivocada (Paulo); c) possa confiar em seu orientador (Consuelo).

\subsection{2) Os mentais de afeição}

Foram encontradas 5 ocorrências de processos mentais de afeição neste campo semântico. Estão nas falas de Rafaela (1), Paulo (2) e Cláudia (2). A diferença entre as aparições dos atores sociais Orientador e Aluno nos processos de afeição é que, aqui, eles revelam como se sentem em relação às possibilidades de desdobramentos dessas relações. Vejamos:

\begin{tabular}{l|l} 
(Rafaela:13) & $\begin{array}{l}\text { às vezes me sinto assim, maravilhosamente bem, porque eu vejo que as } \\
\text { pessoas crescem, as pessoas mudam, as pessoas descobrem, eh, descobrem } \\
\text { caminhos, descobrem respostas, descobrem novidades. }\end{array}$ \\
\hline (Paulo:17) & $\begin{array}{l}\text { Na verdade isso (se sentir refém do tempo do aluno) angustia (afeição) mas } \\
\text { não é o fator mais importante }= \\
\text { (no início da orientação) ele muitas vezes está preocupado (preocupa-se) } \\
\text { com coisas que não são exatamente a sua a sua ênfase, né, }\end{array}$ \\
\hline (Cláudia:20) & $\begin{array}{l}\text { Agora de uma maneira geral eu me sinto feliz por ver esse processo de } \\
\text { engajamento dos alunos né (afeição) } \\
\text { e (me sinto) desafiada pra tentar: eh: criar alguns mecanismos de eh: ah: } \\
\text { interligação eh entre seu grupo de pesquisa com outros grupos de pesquisa } \\
\text { dentro e fora da instituição }\end{array}$
\end{tabular}

Três ocorrências têm em comum uma polaridade positiva relacionada às conquistas do orientador em relação ao aluno inicialmente negativizado, vistos em (Rafaela:13), (Cláudia:20) e (Cláudia:21). A única ocorrência que mantém uma relação de negatividade, (Paulo:18), refere-se a uma circunstância específica, o processo de

\footnotetext{
${ }^{6}$ Aqui, não considerei a oração encaixada para a construção do significado por uma razão de ponderação: "Claudia" contrapõe a ideia da oração principal apenas nesta encaixada; porém ao longo do seu discurso, Claudia defender que o grupo de pesquisa que ela lidera só existe porque foi criado por ela (ela aponta isso em vários outros momentos), e que a relação com os pares é fruto de sua iniciativa (como em "eu acho que NÃO deve ser só aquele que orienta escrever a dissertação. Mas inseri-lo numa comunidade de prática de pesquisadores").

7 A construção de sentido de "queimar etapas" como algo negativo está no cotexto discursivo: "Todo início de orientação é complicado nesse sentido né, você ainda não fala a língua do teu orientando, né, ele muitas vezes está preocupado com coisas que não são exatamente a sua a sua ênfase, né, na questão do do. Ele quer queimar etapas."
} 
orientação. Mas esse não é sustentado pelo cotexto, como vemos em (Paulo:17), que minimiza o efeito negativo do início da orientação em relação aos demais papéis que lhe são atribuídos no Programa de Pós-Graduação citado no contexto da entrevista. ${ }^{8}$

Em quatro ocorrências, o experienciador é o próprio orientador, nas orações principais e em uma delas o Aluno é o experienciador.

Nas quatro ocorrências em que o Experienciador é o Orientador, o fenômeno, encontrado nas orações encaixadas, confirmam sentimentos (2 ocorrências em Cláudia), uma classifica o sentimento da principal (Paulo:17) e uma justifica na prática o motivo do sentir (Cláudia:21).

Atribuir o sentimento ao aluno "ele muitas vezes está preocupado", encontrado em (Paulo:17), pode sugerir a experiência do orientador, que "sabe" sobre o orientando, a ponto de "falar em seu nome".

Nestas cinco ocorrências temos, portanto, um orientador que representa seu fazer por meio de sentimentos mais positivos do que negativos: a) Sente positivamente as conquistas do seu fazer (Rafaela e Cláudia); b) Sente o desafio do seu fazer (Cláudia); c) Sente a angústia do seu fazer (Paulo).

\subsection{3) Os mentais de percepção}

Os processos mentais de percepção surgiram quatro vezes no tocante ao tema "Relações". Assim:

\begin{tabular}{l|l} 
(Rafaela:10) & $\begin{array}{l}\text { Mas no geral eu tento ver aonde que aquele aluno está, no seu próprio } \\
\text { momento acadêmico }\end{array}$ \\
\hline (Paulo:13) & $\begin{array}{l}\text { a orientação me interessa muito como trabalho, como perspectiva de relação } \\
\text { com o aluno }\end{array}$ \\
\hline (Cláudia:18) & $\begin{array}{l}\text { eu vou ver ele crescendo com o que eu to ensinando, não no sentido de que } \\
\text { eu vá passar as coisas pra ele, mas no sentido de vê-lo descobrir coisas, } \\
\text { interagir com os pares, interagir comigo }\end{array}$
\end{tabular}

A partir do mapeamento dos Participantes, em que o experienciador é o Orientador e o fenômeno a orientação (1 ocorrência), a relação como o outro-aluno (1 ocorrência) e o acréscimo do conhecimento do aluno (1 ocorrência), uma interpretação possível é a de que os processos mentais de percepção apontam para a possibilidade de o orientador a) Observar o desenvolvimento do aluno ao longo do processo (Rafaela e Cláudia); e relacionar-se com o aluno para propiciar esse desenvolvimento (Paulo).

\footnotetext{
${ }^{8}$ Apesar de a LSF se ater ao texto como unidade de análise e, metodologicamente, valer-se das orações como recortes dessa unidade básica, esta perspectiva teórica postula a favor da linguagem em seu contexto (HALLIDAY, 1994). Por isso, entendo ser relevante citar que este sujeito de pesquisa referia-se no cotexto de fala a questões políticas de sua atuação (greves e protestos) e a críticas a seus pares, que, segundo ele, não se engajam em questões políticas.
} 


\subsection{4) Algumas considerações sobre os processos mentais no corpus}

O mapeamento dos processos mentais revela o posicionamento dos sujeitos no cumprimento de seu papel social, que parece ser:

- um papel que se cumpre primariamente em sua relação com o aluno;

- um papel que se cumpre com um aluno dependente da experiência, do saber e da coerência do orientador;

- um papel constituído de subjetividade e de afetividade: um orientador que "sente" o seu fazer.

As ocorrências dos processos mentais na fala desses sujeitos sobre as relações em sua atuação podem, finalmente, sugerir o que eles pensam (ver tabela 2 abaixo).

\begin{tabular}{l|l|l} 
Sujeito & Mentais & Pensar por campo semântico \\
\hline Paulo & $37 \%$ & $\begin{array}{l}\text { Pensa/sente/percebe em relação a um aluno negativizado que precisa de } \\
\text { sua atuação competente }\end{array}$ \\
\hline Rafaela & $26 \%$ & $\begin{array}{l}\text { Pensa/sente/percebe em relação a alunos individualizados que precisam } \\
\text { de sua atuação técnica }\end{array}$ \\
\hline Cláudia & $21 \%$ & Pensa/sente/percebe em relação a um aluno-pesquisador aprendiz \\
\hline Consuelo & $16 \%$ & Pensa em relação a um aluno que receberá parceria, ajuda e afeto \\
\hline Todos & $100 \%$ & \multicolumn{2}{l}{} \\
Tabela 2: Resumo dos processos mentais por sujeito
\end{tabular}

\section{2) Os processos comportamentais}

Os processos comportamentais estão, segundo Halliday (1994), entre os materiais e os mentais. O índice de comportamentais (23\%) nas escolhas léxicogramaticais dos sujeitos desta pesquisa ficou, também, entre os materiais (23\%) e os mentais (40\%), o que parece confirmar os constructos teóricos de circularidade e integração dos processos.

Foi relevante observar a recorrência dos processos comportamentais no corpus, já que aparecem significativamente apenas no campo semântico "Relações", o que leva a algumas interpretações possíveis:

- o orientador pensa o seu fazer em relação ao outro (conforme seção anterior) e comporta-se de acordo com o seu pensar;

- o orientador acredita em uma postura hierárquica (tanto de superioridade quanto de "igualdade") em relação ao aluno (conforme seção anterior) e comporta-se de acordo com essa hierarquia.

De acordo com a léxico-gramática presente nos dados e a partir do mapeamento dos Participantes, conforme quadro 01 podemos chegar a algumas construções de sentido, possíveis, neste tópico, principalmente pela escolha dos processos. 


\begin{tabular}{l|l|l|l} 
Comportante & Processos & Comportamento & Totais \\
\hline Orientador/eu & $\begin{array}{l}\text { Instiga } \\
\text { Direciona } \\
\text { Abre os olhos } \\
\text { Torce }\end{array}$ & Aluno $(8 \mathrm{x})$ & 10 \\
& $\begin{array}{l}\text { Fala } \\
\text { Consegue chegar } \\
\text { Consegue mostrar } \\
\text { Tenta chegar } \\
\text { Busca criar } \\
\text { Coloca }\end{array}$ & & \\
& Leva & Grupo de pesquisa & \\
\hline Aluno & \multicolumn{2}{|l}{ Mina } & \\
\hline Totais & & \\
Quadro 1: Mapeamento dos participantes nos processos comportamentais & 1 \\
\hline
\end{tabular}

Vejamos alguns exemplos antes das conclusões:

\begin{tabular}{|c|c|}
\hline $\begin{array}{l}\text { (Rafaela:14) } \\
\text { (Rafaela:15) } \\
\text { (Rafaela:16) } \\
\text { (Rafaela:17) }\end{array}$ & $\begin{array}{l}\text { Eu tenho que instigar ele, } \\
\text { eu tenho que é direcionar ele, } \\
\text { às vezes eu tenho que abrir os olhos dele } \\
\text { Fico torcendo pelo aluno, né, acabar bem }\end{array}$ \\
\hline $\begin{array}{l}\text { (Paulo:21) } \\
\text { (Paulo:23) }\end{array}$ & $\begin{array}{l}\text { OU o contrário, ou (no início da orientação) ele leva um tempo enorme pra } \\
\text { ter sensibilidade pra isso } \\
\text { (no início da orientação o orientador) Não consegue mostrar a ele ou fazê-lo } \\
\text { sentir com você a necessidade de fazer escolhas, né? }\end{array}$ \\
\hline (Cláudia:22) & $\begin{array}{l}\text { eu busco na minha orientação criar (busco criar) realmente o nosso grupo de } \\
\text { pesquisa e dentro do grupo eh- faz parte desse processo de orientação, né? }\end{array}$ \\
\hline (Fátima: 16) & $\begin{array}{l}\text { Eu não vê:jo, não me colo:co ... para os meus alunos como alguém que } \\
\text { TEnha o mapa da mina }\end{array}$ \\
\hline
\end{tabular}

a) O aluno é discursivamente negativizado nessa relação, mesmo quando é agente na forma gramatical, como em "leva um tempo enorme pra ter sensibilidade pra isso" (Paulo:21).

b) O aluno é negativizado nessa relação quando o orientador é agente na forma gramatical, como na sequência (Rafaela:14), (Rafaela:15) (Rafaela:16); e (Cláudia:22)

c) O orientador é valorizado nessa relação, como agente, mesmo quando léxicogramaticalmente impossibilitado nessa relação, como em "a necessidade de fazer escolhas" (Paulo:23), que é do aluno.

d) A relação orientador/aluno é valorizada, como em (Fátima:16).

Desta forma, abrindo os campos semânticos a partir dos sujeitos, podemos interpretar que, nos processos comportamentais,

- o orientador assume o processo de desenvolvimento do aluno (Rafaela, Cláudia);

- o orientador orienta o aluno, com o aluno (Consuelo, Fátima); 
- o orientador (inicialmente) sente-se incapaz de influenciar o aluno (Paulo)

- o aluno (inicialmente) não percebe as expectativas do orientador (Paulo)

\subsection{1) Algumas considerações sobre os processos comportamentais no corpus}

As onze ocorrências dos processos comportamentais no campo semântico "relações" surgiram como pistas para o posicionamento dos Atores Sociais nessas relações. Primeiro porque revela que no fazer orientação, são considerados dois os Atores envolvidos efetivamente nesse processo: o orientador e orientando. Nessa ordem.

A hierarquização desse fazer (tendo o orientador como condutor) e a negativização do aluno nessa relação não parecem ser, em si, dados pessimistas dessa função social. Isto porque, considerando o gênero em que os dados foram gerados, a entrevista, parece ser uma estratégia retórica criar a inferioridade ou dependência do orientando para justificar e/ou valorizar o fazer do orientador. Possibilidade de interpretação que achei cabível, embora conjectural. ${ }^{9}$

Por outro lado, ainda que essa negativização do ator-aluno seja uma visão mais pessimista, pode revelar a crença do Ator Social Orientador como o agente nesse processo de Orientação. Essa parece ser a primeira crença comum a quase todos os sujeitos. Nesse sentido, eles assumem discursivamente que, ao conduzir a relação com o aluno, o orientador conduz literalmente a pesquisa, reproduzindo uma relação assimétrica de poder. A partir dessa crença base, a forma como conduz sua função na relação reflete, mais uma vez, as nuanças do fazer marcado, discursivamente, até aqui, como idiossincrático. A tabela 3 amplia esse mapeamento para os campos semânticos.

\begin{tabular}{l|l|l} 
Sujeito & Comportamentais & Comportamento por campo semântico \\
\hline Paulo & $36 \%$ & Comporta-se sem uma sintonia orientador/aluno \\
\hline Rafaela & $36 \%$ & Comporta-se como condutor do comportamento do aluno \\
\hline Fátima & $18 \%$ & Comporta-se como companheiro do aluno na exploração \\
\hline Cláudia & $9 \%$ & Comporta-se como criadora de grupos de pesquisa \\
\hline Todos & $100 \%$ &
\end{tabular}

Tabela 3: Resumo dos processos comportamentais por sujeito

\footnotetext{
${ }^{9}$ Agradeço tanto à minha orientadora, Dra Gisele de Carvalho pela discussão em torno da pergunta "se o contexto em que desenvolvem seu papel social é tão negativizado por eles, por que orientam de fato?”; quanto à prof. Dra. Anna Elizabeth Balocco pelas discussões em torno do tema "entrevista — o gênero que pode contribuir para 'florear' o próprio fazer”. Ambas as discussões ajudaram a clarear minhas ideias e contribuíram para estas considerações.
} 


\section{3) Os processos relacionais}

Os processos relacionais foram utilizados por três dos sujeitos desta pesquisa: Cláudia ( 2 ocorrências), Rafaela (2 ocorrências) e Paulo ( 2 ocorrências); e somam 13\% das ocorrências categorizadas semanticamente como "relações interpessoais".

\begin{tabular}{l|l} 
(Rafaela:06) & $\begin{array}{l}\text { e eu tenho alunos que têm temperamentos diferentes, têm objetivos } \\
\text { diferentes, agendas diferentes, têm capacidades intelectuais diferentes } \\
\text { (possessivo atributivo) })^{10}\end{array}$ \\
\hline (Paulo:13) & $\begin{array}{l}\text { Todo início de orientação é complicado nesse sentido (de não falarem a } \\
\text { mesma língua) né, (intensivo identificativo) } \\
\text { (Pas ele tem total liberdade pra escolher com que tipo de material ele Vai } \\
\text { trabalhar (possessivo atributivo) }\end{array}$ \\
\hline (Cláudia:17) & $\begin{array}{l}\text { os alunos...eh: podem, eh, têm. Tem eh: lacunas eh: individuais, (possessivo } \\
\text { atributivo) }\end{array}$
\end{tabular}

Como revela o mapeamento dos participantes, os processos relacionais classificam/definem novamente os dois únicos Atores nas relações do fazer orientação: "Orientador" e "Aluno"; e os papéis que esse orientador cumpre: "início de orientação" e "criação de grupo". Aqui ressurge a classificação do fazer do orientador, contudo, um fazer relacionado ao aluno; um fazer também pautado mais nas diferenças do que nas semelhanças, conforme observado nos identificados/atributos (ver quadro 02).

\begin{tabular}{|l|l|l|l|}
\hline Identificado/Atributo & Identificativos & Atributivos & Totais \\
\hline Relação com alunos & & 1 & \\
\hline Alunos diferentes & & 1 & \\
\hline Liberdade de escolha de material & & 1 & \\
\hline Lacunas individuais & & 1 & \\
\hline Complicado & & 1 & \\
\hline Inerente à orientação & 1 & & \\
\hline Totais & 1 & 5 & 6 \\
\hline
\end{tabular}

Quadro 02: Mapeamento dos participantes nos processos relacionais

A partir desse mapeamento, podemos concluir que o fazer do orientador em relação ao aluno é tanto idiossincrático quanto multifacetado.

Os processos relacionais utilizados neste campo semântico foram intensivo identificativo (1), intensivo atributivo (1) e possessivos atributivos (4).

A tabela 4 explica como os sujeitos se relacionam semanticamente com o outro.

\footnotetext{
${ }^{10}$ Aqui, apesar de a oração encaixada apresentar que é o aluno que tem (temperamentos, objetivos, agendas, capacidades intelectuais), vejo-a como pista para revelar a complexidade do fazer do orientador.
} 


\begin{tabular}{l|l|l} 
Sujeito & Relacionais & Relações por campo semântico \\
\hline Rafaela & $33 \%$ & Relaciona (-se) na posse \\
\hline Paulo & $33 \%$ & Relaciona (-se nas) dificuldades \\
\hline Cláudia & $33 \%$ & Relaciona (-se na) criação e na posse \\
\hline Todos & $100 \%$ & \multicolumn{2}{l}{} \\
Tabela 4: Resumo dos processos relacionais por sujeito
\end{tabular}

\subsection{1) Algumas considerações sobre os processos relacionais no corpus}

Os processos relacionais selecionados para este campo semântico (seis ao todo) passaram pelo mesmo crivo dos demais campos semânticos: relacionar entidades na oração principal. Por isso, muitos outros recortes que se remetiam ao aluno ou ao grupo de pesquisa foram desconsiderados para este campo, por permearem orações encaixadas - conforme os recortes abaixo, que foram analisados no campo "fazer" do orientador:
(Cláudia:10) Então (orientar) é- super interessante pra mim, entendeu? Então ver como o aluno: entra e como o aluno vai se desenvolven:do enquanto pesquisador interagindo não só comigo, mas com os outros pares dele, né? (intensivo atributivo)
(Cláudia:11) (orientar) é bom porque ele:: eh:: ... cria, né, esse grupo de pesquisa, de colaboração. (intensivo atributivo)
(Cláudia:12) (orientar)É muito cansativo. Porque você tem eh-, você vê com alunos de históricos diferentes, também, ne, (intensivo atributivo)

Os processos dispensados pela razão acima exposta parecem corroborar as conclusões sugeridas pelos processos relacionais: parecem definir basicamente a complexidade do fazer desse orientador, que atua com o outro, sobre o outro, pelo outro, mesmo quando esse outro (aluno) é o portador/identificador, conforme exemplos abaixo:

(Paulo:14) $\quad$ ele se quiser trabalhar comigo ele tem que trabalhar numa orientação de análise do discurso porque é aquela que eu posso e quero enfim praticar. Mas ele tem total liberdade pra escolher com que tipo de material ele Vai trabalhar. Mas ele tem total liberdade pra escolher com que tipo de material ele Vai trabalhar (possessivo atributivo)

(Cláudia:17) $\quad$ os alunos...eh: podem, eh, têm. Tem eh: lacunas eh: individuais, (possessivo
atributivo)

Assim, os processos relacionais contribuem para interpretar que o orientador valoriza os atributos do próprio papel social. A escolha desses processos serve como pistas para categorizar a atuação do orientador a partir de si - o que parece levar aos conflitos tanto relacionais quanto internos vistos nos demais segmentos do corpus desta pesquisa.

\section{4) Os processos materiais}


Considerei os processos mentais, comportamentais e materiais em nível de interligação, ou seja, como pistas complementares para a interpretação do fazer do orientador. Isso porque, segundo a LSF (HALLIDAY, 1994), os processos não deveriam ser vistos de forma independente, nem hierárquica.

Dessa forma, assim como os demais processos, os onze processos materiais e seus participantes parecem contribuir para a construção de sentido de um fazer que se inicia no próprio orientador, sugerindo novamente uma relação assimétrica em relação ao aluno. Vejamos os dados mapeados no quadro 02 :

\begin{tabular}{l|l|l|l} 
Ator & Processos & Meta/Extensão/Beneficiário/Afetado & Totais \\
\hline Orientador (7x) & Pressionar & Aluno (3x) & 7 \\
& Ajudar & & \\
& Recebe & & \\
& Oriento (2x) & Para o desenvolvimento do aluno (2x) & \\
& Faz & Desenvolvimento do aluno & \\
& Andar & Com aluno & 3 \\
\hline Aluno (3x) & Emenda & Níveis & \\
& Descubra & Interesse de trabalho & \\
\hline O caminho & Faz & Mestrado & 1 \\
\hline Totais & Deu & (Não) frutos & 11
\end{tabular}

Quadro 02: Mapeamento dos participantes nos processos materiais

Os exemplos extraídos do corpus possibilitarão uma visão mais detalhada dos dados:

\begin{tabular}{l|l} 
(Rafaela:06) & e ajudar ele até chegar o produto final que é a a dissertação já pronta. \\
\hline (Paulo:07) & $\begin{array}{l}\text { (você recebe muita gente) com experiência muito: limitada } \\
\text { (Paulo:09) }\end{array}$ \\
E fazer com que o cara descubra com você algum interesse de trabalho \\
& $\begin{array}{l}\text { O cara faz um mestrado porque não tem um lugar pra trabalhar OU tá } \\
\text { trabalhando muito subempregado: enfim. }\end{array}$ \\
\hline (Cláudia:14) & $\begin{array}{l}\text { você tem que fazer o desenvolvimento de cada alu:no, o desenvolvimento do } \\
\text { gru:po, não é, de pesqui:a. }\end{array}$ \\
\hline (Fátima:14) & $\begin{array}{l}\text { Então... à medida em que a gente aponta o caminho é pra é pra eu andar } \\
\text { com o aluno. }\end{array}$
\end{tabular}

Em cinco das onze ocorrências dos processos materiais, o orientador é colocado como aquele que atua em relação ao aluno (pressiona, ajuda, faz), conforme exemplificado em (Rafaela:06), (Cláudia:14) e (Fátima:14).

Nesses processos, o orientador aparece uma única vez como afetado (Paulo:07), o que possibilita a interpretação de que maus alunos não são escolha dos orientadores.

Três processos materiais relacionam a agência do orientador à formação de grupos de pesquisas. Essa escolha revela que o orientador deixa de ver o orientando

\footnotetext{
${ }^{11}$ Andar, aqui entendido como "fazer/desenvolver trabalho com".
} 
como aluno, ou como um pesquisador, mas como o componente de um grupo de futuros pesquisadores, como em (Cláudia:14).

Em duas ocorrências, como em (Paulo:10), o orientando é o Ator do processo, mas a oração encaixada amplia o sentido mostrando que esse aluno age com motivação equivocada para a inserção em pesquisa.

A análise dos recortes possibilita o esquema representado pela figura 1.

\begin{tabular}{|l|l|l|l|}
\hline $\begin{array}{l}\text { Ator } \\
\text { Social } \\
\text { Ativo }\end{array}$ & Orientador & $\begin{array}{l}\text { age em relação à motivação do aluno } \\
\text { age em relação às atitudes do aluno } \\
\text { caminha com o aluno }\end{array}$ & $\begin{array}{l}\text { Paulo } \\
\text { Rafaela e Cláudia } \\
\text { Fátima }\end{array}$ \\
\cline { 2 - 4 } & Aluno & faz mestrado com motivação equivocada & Paulo \\
\hline $\begin{array}{l}\text { Ator } \\
\text { Social } \\
\text { Passivo }\end{array}$ & Orientador & recebe alunos sem consciência acadêmica & Paulo \\
\hline
\end{tabular}

Figura 1: Mapeamento dos Atores Sociais nos processos materiais

Apesar de a figura 1 aparecer deslocada das demais análises, que não foram assim desenhadas, considerei pertinente observar os papéis sociais nos processos materiais, porque através deles podemos mapear como de fato agem em suas relações, neste caso, com o que eles consideram ser o ator que justifica o seu fazer - o aluno.

\subsection{1) A identidade de projeto}

As construções discursivas que destoam da definição do fazer do orientador estão em Fátima, cuja experiência acadêmica está a serviço das descobertas conjuntas. Isso se revela nos dois recortes discursivos que apresentam processos materiais:

\begin{tabular}{l|l} 
(Fátima:14) & $\begin{array}{l}\text { Então... à medida em que a gente aponta o caminho é pra é pra eu andar } \\
\text { com o aluno. }\end{array}$ \\
\hline (Fátima:15) & $\begin{array}{l}\text { De repente da um - ali não deu, não deu fruto, então a gente tem que pensar } \\
\text { num outro caminho. }\end{array}$
\end{tabular}

Nesses processos, ainda que os Atores sejam o "orientador" (Fátima:14) e o "caminho" (Fátima:15); ainda que o caminho tenha sido apontado pelo orientador; ou ainda que o caminho não seja o melhor, é possível perceber que: a) o aluno é inserido no processo de caminhada e de redescoberta dos caminhos; ${ }^{12}$ e b) o orientador reconhece discursivamente que pode estar equivocado em alguns apontamentos de caminhos.

\footnotetext{
${ }^{12}$ Observando a utilização de "a gente" no recorte (Fátima:14) e pensando em um paralelismo sintático, eu poderia inferir que "a gente" de (Fátima:15) refere-se a própria orientadora que, portanto, pensaria pelo aluno. O fato de a expressão "a gente" no recorte (Fátima:15) estar em oração encaixada, isenta, portanto, da minha análise, deixa-me confortável para não inferir interpretações aqui.
} 


\subsection{2) Algumas considerações sobre os processos materiais no corpus}

Os processos materiais (11 ocorrências que representam 23\% dos processos neste campo semântico) reiteram a crença de que a orientação é feita nas relações Orientador-Orientando. Se a função orientar recebe uma carga semântica de "condutor", o orientando parece receber a carga semântica de "aluno", aquele que precisa ser "reformado" no processo educacional para ser "transformado em...", conforme o mapeamento dos participantes vistos ao longo da subseção.

Os sujeitos de pesquisa (menos Fátima) apontam discursivamente para uma ressignificação do papel do professor que atua com orientação. Parece ser um papel específico em um segmento específico, com atribuições específicas e especializadas. Segundo a prof. Dra. Kátia Tavares esse resultado pode ter surgido do próprio objetivo do trabalho: pesquisar a especificidade do papel do orientador. A propriedade desse argumento nos conduz, portanto, a lançar ênfase ao fato de o sujeito Fátima agregar ao orientador um valor amplo do ser professor.

Enquanto os sujeitos da pesquisa, discursivamente, sugerem para o orientador o papel social de "motivar para a pesquisa" - e não apenas para o produto-dissertação, conforme (Cláudia:14), sugerem também que esse papel social se materializa em alunoorientando que não desenvolve autonomia, conforme (Rafaela:06), reproduzindo, portanto, a ideia de aluno herdada dos demais segmentos educacionais.

Essas conclusões partem do mapeamento dos processos/participantes, tabela 05.

\begin{tabular}{l|l|l} 
Sujeito & Materiais & Ações por campo semântico \\
\hline Paulo & $36 \%$ & Age sobre o aluno \\
\hline Cláudia & $27 \%$ & Age sobre o aluno \\
\hline Fátima & $18 \%$ & Age nas relações \\
\hline Rafaela & $18 \%$ & Age sobre o aluno \\
\hline Todos & $100 \%$ & \multicolumn{2}{l}{} \\
\multicolumn{2}{l}{ Tabela 05: Resumo dos processos materiais por sujeito }
\end{tabular}

\section{Considerações finais}

Na perspectiva dos objetivos centrais da pesquisa de mestrado (mapear o campo social orientar), essas abordagens espontâneas, de temas que não haviam sido evocados linguisticamente nas perguntas formuladas aos participantes, revelariam os temas/questões importantes do ponto de vista dos próprios atores desse fazer, e não de quem vê de fora.

Assim, a subcategorização desses campos semânticos e as análises linguísticas detalhadas contribuíram para mapear o que os sujeitos têm a dizer, mas que ninguém lhes pergunta.

Diferentemente do tema evocado, mostrado na dissertação, em que os processos que mais aparecem são os relacionais (45\%), nos campos semânticos não evocados nas perguntas da entrevista, a maior incidência dos processos é dos mentais (38\% do corpus total da pesquisa de mestrado), conforme tabela abaixo, que resume processos e retoma o uso dos mesmos por participante. 


\begin{tabular}{|c|c|c|c|c|c|c|}
\hline & Mentais & Materiais & Relacionais & Comportamentais & Totais & \\
\hline Rafaela & 5 & 2 & 2 & 4 & 13 & $28 \%$ \\
\hline Paulo & 7 & 4 & 2 & 4 & 17 & $37 \%$ \\
\hline Consuelo & 2 & & & & 2 & $4 \%$ \\
\hline Cláudia & 4 & 3 & 2 & 1 & 10 & $22 \%$ \\
\hline Fátima & & 2 & & 2 & 4 & $9 \%$ \\
\hline Totais & 18 & 11 & 6 & 11 & 46 & $100 \%$ \\
\hline
\end{tabular}

Resumo dos processos por sujeito

Nas relações interpessoais, os sujeitos da pesquisa: (I) parecem relacionar-se prioritariamente com os alunos, independentemente da instituição em que atuam; (II) marcam uma relação assimétrica de poder com o aluno; e (III) descrevem seu fazer como complexo, devido a novas demandas marcadas pela passividade do aluno.

Com o recurso do tratamento linguístico minucioso dos dados da Linguística Sistêmico-Funcional (LSF), podemos descortinar as brechas que possam apontar para transformações quanto ao tema orientação de dissertações de mestrado. Isso porque há que haver um espaço para pensar a importância das produções científicas do aluno de mestrado, o que torna propício pensar o espaço da orientação da dissertação como possibilidade de análise dessa questão.

Assim, fica, dos recortes discursivos, um convite a novas pesquisas sobre o discurso do orientador, jogando luz sobre sua voz, mas também contribuições diretas e significativas aos estudos em Linguística e Linguística Aplicada, ouvindo as vozes do Sul, em suas realidades (Moita Lopes 2008).

\section{Referências}

ALVEZ-MAZZOTI, A. J.; GEWANDSZNAJDER, Fernando. O método nas ciências naturais e sociais: pesquisa quantitativa e qualitativa. 2 ed. São Paulo: Pioneira, 1999.

BIANCHETTI, L.; MACHADO, A. M. (orgs). A Bússola do escrever - desafios e estratégias na orientação e escrita de teses e dissertações. 2 ed. São Paulo: Cortez, 2006.

DIJK, T. A. V. Discurso e Poder. 2 ed. São Paulo: Contexto, 2010

FAIRCLOUGH, Norman . Discurso e mudança social. Brasília: UnB, 2001.

FLECHA, B. S. C. Mestrandos à deriva: cadê o orientador? ALEMG, 2003. 〈www.almg.gov.br/educacao/sobre.../mestrandos_a_deriva.pdf $>$, Acesso $27 / 05 / 2010$.

GOUVEIA, C. A. M. Texto e gramática: uma introdução à Linguística SistêmicoFuncional. Vol. 16. Matraga, Rio de Janeiro, 2009. p.13-47. 
GHIO, E.; FERNANDEZ, M. D. Manual de Linguística Sistémico Funcional: El enfoque de M. A. K. Halliday y Hasan - Aplicaciones a La lengua española. Santa Fé. Universidad Nacional Del Litoral, 2005.

HALLIDAY, M. A. K.; HASAN, R. Language, context and text: aspects of language in a social-semiotic perspective. Oxford University Press, 1989.

HALLIDAY, M. A. K. An introduction to functional grammar. 2 ed. London: Edward Arnold, 1994.

HALLIDAY, M. A. K.; MATHIESSEM, C. M. I. M. An introduction to functional grammar. 3 ed. London: Edward Arnold, 2004.

MOITA LOPES, L. P. Linguística Aplicada e Vida Contemporânea. In: MOITA LOPES, Luiz Paulo (org). Por uma linguística indisciplinar. 2 ed. São Paulo: Parábola, 2008. p. $85-107$

NEVES, M. H. M. A gramática funcional. São Paulo: Martins Fontes, 1997.

SAVIANI, D. A pós-graduação em educação no Brasil: pensando o problema da orientação. In: BIANCHETTI, L.; MACHADO, A. M. (orgs.) A Bússola do escrever desafios e estratégias na orientação e escrita de teses e dissertações. 2 ed. São Paulo: Cortez, 2006. p. 135-163. 